\title{
Inhibition of Rhizobium trifolii by Yeast Extracts or Glycine is Prevented by Calcium
}

\author{
By MARIE T. SHERWOOD* \\ Agricultural Institute, Johnstown Castle, Wexford, Ireland and \\ Biochemistry Department, University College, Dublin, Ireland
}

(Accepted for publication 5 February 1972)

\begin{abstract}
SUMMARY
Several yeast water preparations and commercial yeast extracts varied in their toxicity to two strains of Rhizobium trifolii. Strains of $R$. japonicum and R. leguminosarum were also susceptible to yeast extract, while strains of $R$. meliloti were resistant.

An interaction between glycine and monovalent cations was the main cause of yeast extract toxicity. Divalent cations, notably $\mathrm{Ca}^{2+}$, added to inhibitory media prevented the toxicity and enhanced growth with increased concentrations of yeast extract.
\end{abstract}

\section{INTRODUCTION}

Yeast extract mannitol agar (YEMA) is the most commonly used medium for the culture of rhizobia, and is made from either yeast water preparations, or commercial yeast extract powders and pastes. Attempts to recover Rhizobium trifolii quantitatively by plate counts, gave anomalous results which were traced to inhibition by commercial yeast extracts.

Toxicity of yeast extracts to other bacterial species has been reported occasionally but there have been very few references to inhibition of rhizobia. Jordan (I965) reported poor growth, with apparent bacteroid formation, of Rhizobium leguminosarum in mannitol broth containing $0.35 \%$ Difco yeast extract. On the other hand, many workers have described experiments with rhizobia in media containing 0.5 to $I \%(w / v)$ commercial yeast extracts, without comment on the growth yield.

This paper reports an examination of the effects of a number of yeast extracts on the growth of Rhizobium trifolii.

\section{METHODS}

Media. Unless otherwise stated, YEMA contained (g/l): mannitol, Io; $\mathrm{K}_{2} \mathrm{HPO}_{4}, 0.5$; $\mathrm{MgSO}_{4} .7 \mathrm{H}_{2} \mathrm{O}, 0.2 ; \mathrm{NaCl}, 0 . \mathrm{I} ;$ Oxoid no. 3 agar, ${ }_{5} ; \mathrm{CaCO}_{3}, 3$ (Fred, Baldwin \& $\mathrm{McCoy}$, 1932). Commercial yeasts extracts or yeast water preparations were added at specified concentrations $\mathrm{w} / \mathrm{v}$ for extracts and $\mathrm{v} / \mathrm{v}$ for yeast water. Standard YEMA contained $0.3 \%$ Oxoid yeast extract (' $\mathrm{L} 20^{\prime}$ ' Batch I I 8). All media were adjusted to $\mathrm{pH} 6.8$; additives were sterilized separately. Chemicals were analytical reagent grade where possible.

Yeast extract mannitol broth (YEMB) was YEMA without agar. The medium was boiled, cooled, while the $\mathrm{CaCO}_{3}$ settled, then the supernatant liquid was decanted.

Yeast extracts. Six commercial yeast extract preparations were used: two Oxoid pastes (L 20), batches II 8 and I23; three Oxoid powders (L 2I), batches 2233, 2719 and 2878; one Difco powder, batch 493534 .

* Present address: Agricultural Institute, Wexford, Ireland. 
Yeast water preparations. Fresh samples of both baker's (Cork Yeast Company, Cork, Ireland) and brewer's (courtesy Messrs A. Guinness, Son \& Co. (Dublin) Ltd) yeast were used. The brewer's yeast was supplied unwashed and half this material was washed with $\mathrm{NaCl}(0.9 \%, w / v)$. The yeast samples were autolysed with an equal weight of water, at various temperatures and for different times, then cooled, centrifuged and the decanted supernatant liquids were autoclaved at $10 \mathrm{lb} / \mathrm{in}^{2}$ for $20 \mathrm{~min}$.

Strains and culture methods. Two strains each of Rhizobium trifolii (J712, J777); Rhizobium

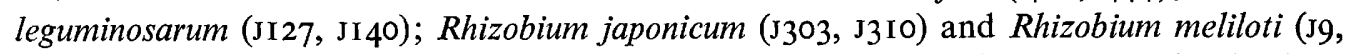
JIO) were from the culture collection at Johnstown Castle. All had been maintained on standard YEMA for a considerable time. For plate counts, the organisms from four-day-old slopes were shaken in $100 \mathrm{ml}$ of $0.5 \%(\mathrm{w} / \mathrm{v}) \mathrm{NaCl}$ and $\mathrm{I} \mathrm{ml}$ samples of these suspensions and of serial decimal dilutions were plated in duplicate on the test media. Colonies were counted after four days; cultures and plates were incubated at $25^{\circ} \mathrm{C}$.

For inoculation of YEMB, the organisms from slopes were suspended in water to about ${ }_{10}^{8} / \mathrm{ml}$. Cultures $(20 \mathrm{ml})$ were grown in $100 \mathrm{ml}$ round-bottomed sidearm flasks using $\mathrm{I} \mathrm{ml}$ of inoculum on a gyrotary shaker (New Brunswick Scientific Instrument Co., New Jersey, U.S.A.) at $140 \mathrm{rev} . / \mathrm{min}$. Growth was measured with a photoelectric nephelometer (Evans Electroselenium Ltd, Harlow, Essex) and bacterial numbers obtained by comparing readings with curves made for each strain by plotting nephelometer readings in standard YEMB (containing $0.022 \%(\mathrm{w} / \mathrm{v}) \mathrm{CaCl}_{2} \cdot 6 \mathrm{H}_{2} \mathrm{O}$ ) against viable counts on standard YEMA. Total microscopic counts were made on all cultures at the onset of the stationary phase to ensure that increases turbidity had been due to increase in numbers of organisms.

Analyses. Total nitrogen content of the commercial yeast extracts was determined by Kjeldahl analysis. The $\alpha$-amino nitrogen content of commercial yeast extracts and yeast water preparations was determined using Sorensen's formol titration (cited by Mann \& Saunders, 1960), with leucine as standard.

Potassium was determined by flame photometry (Byrne, 1968), sodium and calcium by atomic absorption spectroscopy (Frey, I964) and chloride by titration using $\mathrm{AgNO}_{3}$ (Byrne, I968).

Toxic factor. Toxic factor (TF) was recognized by adding a sample of the test solution to standard YEMA plates, inoculating with a suspension of Rhizobium trifolii $57 \mathrm{I} 2$ containing about $10^{5}$ organisms, and observing decrease or absence of growth. TF was characterized as follows.

A sample $(5 \mathrm{ml})$ of an aqueous solution $(20 \%$, w/v) of Difco yeast extract was added to a Sephadex G-15 (Pharmacia, Uppsala, Sweden) column $(\mathrm{I} \cdot 5 \times 35 \mathrm{~cm})$. Using water as eluent, $60 \times 2 \mathrm{ml}$ fractions were collected and $0.2 \mathrm{ml}$ of each fraction tested for TF. The toxic fractions were pooled and concentrated on a rotary evaporator before transferring to a column $(2 \times 35 \mathrm{~cm})$ packed with Amberlite IR-I20 resin, hydrogen form (BDH Chemicals Ltd, Poole, Dorset) in water. The column washings with $(a)$ water $(200 \mathrm{ml})$ followed by $(b)$ $0 . \mathrm{I} \mathrm{M}-\mathrm{HCl}(200 \mathrm{ml})$ and subsequently $(c) 0 . \mathrm{I} \mathrm{M}-\mathrm{NH}_{4} \mathrm{OH}(200 \mathrm{ml})$ were each dried under vacuum, redissolved in water and tested for TF.

Two solvents, described by Levy \& Chung (1953), were used for double chromatography on Whatman no. 3 paper: A, $n$-butanol + acetic acid + water $(4+\mathrm{I}+5, \mathrm{v} / \mathrm{v}) ; \mathrm{B}$, phenol $+m$ cresol + O.I M-borate buffer, $\mathrm{pH} 9 \cdot 3(25+25+7, \mathrm{w} / \mathrm{v} / \mathrm{v})$.

A solution containing the TF was streaked uniformly across the top of a sheet of chromatography paper and the chromatogram developed in solvent $\mathrm{A}$ for $\mathrm{I} 8 \mathrm{~h}$ at $18^{\circ} \mathrm{C}$. The dried paper was cut into a series of strips, parallel to the origin streak and each $\mathrm{I} \mathrm{cm}$ wide, and each was eluted with water. Eluates were concentrated, autoclaved and tested for TF. This 


\title{
Table I. Effect of different commercial yeast extracts on plate counts of Rhizobium trifolii
}

\begin{abstract}
YEMA was prepared using six commercial yeast extracts at both $0.3 \%$ and $0.5 \%$. The numbers of viable organisms on slopes of $\mathrm{J} 7 \mathrm{I} 2$ and $\mathrm{J} 777$ were determined by plating serial decimal dilutions in $0.5 \%(\mathrm{w} / \mathrm{v}) \mathrm{NaCl}$ on all twelve YEMA media and counting colonies after 4 days at $25^{\circ} \mathrm{C}$. All counts are averages from duplicate plates. Total nitrogen was determined by Kjeldahl analysis, $\alpha$-amino nitrogen was determined by formol titration. All figures are averages from duplicate analyses.
\end{abstract}

\begin{tabular}{|c|c|c|c|c|c|c|}
\hline \multirow[b]{3}{*}{ Yeast extract (YE) source } & \multirow{3}{*}{$\begin{array}{l}\text { Total N } \\
\text { (\% of dry } \\
\text { weight })\end{array}$} & \multirow{3}{*}{$\begin{array}{l}\alpha \text {-Amino-N } \\
(\% \text { of dry } \\
\text { weight) }\end{array}$} & \multicolumn{4}{|c|}{ Bacterial counts $\left(\times 1 \mathrm{IO}^{-6}\right)$} \\
\hline & & & \multicolumn{2}{|c|}{ Strain $\mathbf{J} 777$} & \multicolumn{2}{|c|}{ Strain J7I 2} \\
\hline & & & $0.3 \%$ YE & $0.5 \% \mathrm{YE}$ & $0.3 \% \mathrm{YE}$ & $0.5 \% \mathrm{YE}$ \\
\hline Oxoid Batch I 18 (paste) & $8 \cdot 2 *$ & $2 \cdot 72 *$ & $6800 \dagger$ & 7300 & $8400 \dagger$ & I IO \\
\hline Oxoid Batch 123 (paste) & $8 \cdot 4^{*}$ & $2 \cdot 94^{*}$ & 6500 & 3000 & 5900 & $2 I$ \\
\hline Oxoid Batch 2233 (powder) & $10 \cdot 7$ & $3 \cdot 62$ & 4700 & $2 \cdot I$ & 170 & 20 \\
\hline Oxoid Batch 2719 (powder) & $7 \cdot 5$ & I. 49 & 7000 & 6800 & 6200 & 7000 \\
\hline Oxoid Batch 2878 (powder) & $9 \cdot 7$ & $2 \cdot 54$ & 8400 & 20 & 180 & 0.02 \\
\hline Difco Batch 493534 (powder) & $10 \cdot 8$ & $4 \cdot 14$ & 2100 & 0.5 & 60 & 0 \\
\hline
\end{tabular}

procedure of cutting the paper in strips, eluting and testing for TF will be referred to as 'strip analysis'.

Toxic eluates recovered from chromatogram A were restreaked on chromatography paper and developed in solvent B for $24 \mathrm{~h}$ at $\mathrm{I} 8^{\circ} \mathrm{C}$. Strip analysis of the thoroughly dried chromatogram located the TF.

Electrophoresis. Solutions containing TF were streaked on strips of chromatography paper before electrophoresis in either acetic acid $+88 \%(\mathrm{w} / \mathrm{v})$ formic acid + water $(87+47+866$, $\mathrm{v} / \mathrm{v}$ ) buffer, $\mathrm{pH} \mathrm{I} \cdot 9$, at $6 \mathrm{~V} / \mathrm{cm}$ for $2 \mathrm{~h}$, or $0 . \mathrm{I}$ m-potassium phosphate buffer, $\mathrm{pH} 6.5$, and run at $6 \mathrm{~V} / \mathrm{cm}$ for $2 \mathrm{~h}$.

Glycine (Sigma, London) markers spotted on the outer edges of the paper were located by spraying with ninhydrin $\left(0.5 \%, \mathrm{w} / \mathrm{v}\right.$ in $n$-butanol) and heating at $100{ }^{\circ} \mathrm{C}$ for $10 \mathrm{~min}$.

Amino acid maps and semiquantitative glycine analyses. Aqueous solutions $(5 \%, \mathrm{w} / \mathrm{v})$ of each of the six commercial yeast extracts were spotted on paper for two dimensional chromatography in solvents A and B. The developed chromatograms were sprayed with ninhydrin and heated to reveal spots.

The paper containing the glycine spot revealed by ninhydrin from each map was cut into small pieces, immersed in aqueous ethanol $(80 \%, \mathrm{v} / \mathrm{v})$ and the extinction of the solution at $570 \mathrm{~nm}$ read on a spectrophotometer (Unicam, Cambridge). Glycine standards were chromatographed and treated similarly and blanks were cut from the paper close to the glycine spots.

Adaptation of strains to media containing high glycine concentration. The test strains of Rhizobium trifolii were serially cultured on standard YEMA containing incremental additions of glycine $(0.002$ to $0.2 \%, \mathrm{w} / \mathrm{v})$ for ten successive transfers at intervals of I week.

\section{RESULTS}

Plate counts on YEMA containing different yeast extracts. Yeast extract mannitol agar was prepared using six commercial yeast extracts at both $0.3 \%$ and $0.5 \%$. Plate counts on all I 2 resulting media (Table $\mathbf{I}$ ), showed that the toxicity of the media varied considerably. 
There was a correlation between toxicity and both $\mathrm{N}$ and amino- $\mathrm{N}$ content of the extracts, to which Oxoid 2878 was an exception, having an amino- $N$ content low relative to its toxicity.

Strain J7I 2 was more susceptible to the toxic factor, as poor recoveries of this strain were obtained with $0.3 \%$ of three of the powdered yeast extracts. In general, the results with the two yeast extract pastes were similar, whereas the powders showed considerable variation. Both strains were inhibited by $0.5 \%$ of all powders except Oxoid 2719 , which was toxic to neither strain at $0.5 \%$ or at $1.0 \%$. Colony size decreased as yeast extract concentration increased and in some instances, counts had to be confirmed under magnification.

Yeast water preparations from both bakers' and brewers' yeast also contained the toxic factor and its concentration in the yeast water increased with longer autolysis. Again there seemed to be a relationship between the toxicity of each yeast water preparation and its amino nitrogen content. The autolysate from the washed brewers' yeast had almost double the amino nitrogen content of the autolysate from the unwashed sample, and was considerably more toxic.

Characterization of the toxic factor. The TF was heat stable and was removed from Difco yeast extract powder by repeated extractions with methanol or aqueous ethanol $(80 \%, v / v)$, but was insoluble in absolute ethanol, ether, benzene or chloroform.

An aqueous solution of Difco yeast extract was fractionated on Sephadex G-15. The TF was eluted in a broad peak (fractions I 8 to 26), concentrated and adsorbed on a cation exchange resin. It was not eluted with water, but a secondary toxic factor $(\mathrm{X})$ was eluted with dilute $\mathrm{HCl}$ and the primary toxic factor $(\mathrm{Y})$ was present in the fraction eluted by $\mathrm{NH}_{4} \mathrm{OH}$.

Identification of toxic factor $X$. Toxic factor $\mathrm{X}$ had $R_{f} 0.26$ in solvent $\mathrm{A}$ but could not be located on the chromatogram developed in solvent $\mathrm{B}$. The substance at $R_{f} 0.26$ in solvent $\mathrm{A}$ gave an alkaline reaction, and strip analysis showed $\mathrm{Na}^{+}$and $\mathrm{K}^{+}$in this area.

Identification of toxic factor $Y$. Toxic factor $\mathrm{Y}$ was ninhydrin-positive, having $R_{f} 0.2$ in solvent $\mathrm{A}$ and $R_{f} 0.35$ in solvent $\mathrm{B}$, as did glycine. The factor had the same electrophoretic mobility as glycine at both $\mathrm{pH} 6 \cdot 5$ and $\mathrm{pH} \mathrm{I} \cdot 9$, and could not be separated from glycine by two dimensional chromatography.

The effects of $\mathrm{Na}^{+}, \mathrm{K}^{+}$and glycine on the growth of Rhizobium trifolii in YEMB. Glycine and $\mathrm{Na}^{+}$were tested both singly and in combination against growth of $R$. trifolii J7I 2 and $\mathrm{J} 777$ in YEMB containing $0.1 \%$ Oxoid 2233 powder, to which $\mathrm{NaCl}$, in addition to the $0.0 \mathrm{I} \%$ normally added to YEM preparations, and glycine, in addition to whatever glycine was present in the $0 . \mathrm{I} \%$ yeast extract, were added. The effects on strain J7I 2 are shown in Table 2, and similar results were obtained with strain $\mathrm{J} 777$. There was an interaction with all combinations of the additives. The effects of either $\mathrm{NaCl}$ or glycine as single additives are difficult to assess, and may in fact have been due to an interaction since both glycine and $\mathrm{NaCl}$ were already present in the test medium.

Equivalent amounts of either $\mathrm{KCl}, \mathrm{NH}_{4} \mathrm{Cl}$ or $\mathrm{Na}_{2} \mathrm{SO}_{4}$, when substituted for $\mathrm{NaCl}$ gave similar trends, both with and without added glycine.

The effects of divalent cations on the growth of Rhizobium trifolii in YEMB. Salts of some divalent cations not only prevented glycine toxicity, but caused increased growth. Divalent cations also prevented yeast extract toxicity to strains $\mathrm{J} 7 \mathrm{I} 2$ and $\mathrm{J} 777$ (Table 3 ) by various extracts. Without added divalent cations neither strain grew. Calcium ion was much the most effective and the response to $\mathrm{Ca}^{2+}$ (and other divalent cations) occurred whether or not $\mathrm{CaCO}_{3}(3 \mathrm{~g} / \mathrm{l})$ was added to the medium. Soluble calcium prevented $\mathrm{NaCl}$ and glycine toxicity (Table 4$)$. 
Table 2. Effect of added $\mathrm{Na}^{+}$and glycine on growth of Rhizobium trifolii in YEMB

The medium was YEMB containing $0.1 \%$ Oxoid 2233. Glycine and $\mathrm{NaCl}$ solutions were autoclaved separately and added aseptically to the medium prior to inoculation with an aqueous suspension of strain J7 2. All figures are averages from duplicate flasks.

\begin{tabular}{cccc} 
& \multicolumn{3}{c}{ Bacterial numbers $/ \mathrm{ml}\left(\times 10^{-8}\right)$ at $48 \mathrm{~h}$} \\
\cline { 2 - 2 }$\%$ added & $\overbrace{0.002}^{\text {Glycine }(\%)}$ & 0.003 \\
0 & 33 & 29 & 23 \\
0.01 & 32 & 21 & 17 \\
0.02 & 29 & 14 & 6 \\
0.03 & 22 & 9 & 3
\end{tabular}

Table 3. Effectiveness of divalent cations in preventing yeast extract toxicity to Rhizobium trifolii

The test medium was YEMB containing $0.5 \%$ Oxoid 2878 . The salts were autoclaved separately and added aseptically to the medium prior to inoculation with aqueous suspensions of the two Rhizobium trifolii strains. Bacterial numbers were determined as described in Methods. All figures are averages from duplicate flasks.

$\begin{array}{lccc}\text { Additive } & \begin{array}{c}\text { Final concn in } \\ \text { medium }(\% \mathrm{w} / \mathrm{v})\end{array} & \overbrace{\text { Strain J7I2 }}^{\text {Bacterial numbers } / \mathrm{ml}\left(\times \mathrm{IO}^{-8}\right) \text { at } 48 \mathrm{~h}} & \text { Strain J777 } \\ \mathrm{MgCl}_{2} .6 \mathrm{H}_{2} \mathrm{O} & 0.020 & 0.5 & 0.5 \\ \mathrm{MnCl}_{2} .4 \mathrm{H}_{2} \mathrm{O} & 0.020 & 9.0 & 6.5 \\ \mathrm{CaCl}_{2} .6 \mathrm{H}_{2} \mathrm{O} & 0.022 & 42.0 & 56.0 \\ \mathrm{BaCl}_{2} .2 \mathrm{H}_{2} \mathrm{O} & 0.024 & 0.5 & 0.5 \\ \mathrm{SrCl}_{2} .6 \mathrm{H}_{2} \mathrm{O} & 0.027 & 8.0 & 24.0 \\ \text { None } & & <0.2 & <0.2\end{array}$

\section{Table 4. Effectiveness of $\mathrm{Ca}^{2+}$ in preventing $\mathrm{Na}^{+}$and glycine toxicities to Rhizobium trifolii}

The test medium was YEMB containing $0.1 \%$ Oxoid 2878 . Glycine (gly), $\mathrm{NaCl}$ and $\mathrm{CaCl}_{2} \cdot 6 \mathrm{H}_{2} \mathrm{O}$ solutions were autoclaved separately and added aseptically to $0.003 \%, 0.03 \%$ and $0.022 \%$ respectively. Bacterial numbers were determined as described in Methods. All figures are averages from duplicate flasks.

\section{Additive}

None
$\mathrm{Ca}^{2+}$
gly
gly $+\mathrm{Ca}^{2+}$
$\mathrm{NaCl}$
$\mathrm{NaCl}+\mathrm{Ca}^{2+}$
$\mathrm{NaCl}+\mathrm{gly}$
$\mathrm{NaCl}+\mathrm{gly}+\mathrm{Ca}^{2+}$

$\overbrace{\text { Strain J712 }}^{\text {Bacterial numbers } / \mathrm{ml}\left(\times \mathrm{IO}^{-3}\right) \text { at } 48 \mathrm{~h}}$

$\begin{array}{rc}29 & 23 \\ 32 & 32 \\ 23 & 7 \\ 31 & 29 \\ 25 & 5 \\ 31 & 32 \\ 6 & 0 \cdot 2 \\ 31 & 26\end{array}$

Visual assessment of amino acid composition of commercial yeast extracts. Before assaying glycine in the commercial yeast extracts, two-dimensional amino acid maps were prepared using solvents $\mathrm{A}$ and $\mathrm{B}$, which showed that glutamic acid, serine, alanine, histidine, methionine + valine and leucine + isoleucine were present in highest concentrations with lesser amounts of aspartic acid, glycine, asparagine, lysine, phenylalanine, and proline and only 
Table 5. Glycine, sodium chloride and calcium content of commercial yeast extracts Assays were made as described in Methods.

$\begin{array}{cccc}\text { Yeast extract sample } & \begin{array}{c}\text { Glycine } \\ (\%)\end{array} & \begin{array}{c}\mathrm{NaCl} \\ (\%)\end{array} & \begin{array}{c}\text { Calcium } \\ (\%)\end{array} \\ \text { Oxoid 2719 } & 0 \cdot 2 & 3 \cdot 6 & 0 \cdot 18 \\ \text { Oxoid I23 } & \mathrm{I} \cdot 2 & 3 \cdot 6 & 0 \cdot 14 \\ \text { Oxoid 2878 } & 1 \cdot 0 & 7 \cdot 4 & 0 \cdot 19 \\ \text { Oxoid 2233 } & \mathrm{I} \cdot 4 & 2 \cdot 5 & 0 \cdot 15 \\ \text { Difco 493534 } & \mathrm{I} \cdot 7 & 4 \cdot 9 & 0.2 \mathrm{I}\end{array}$

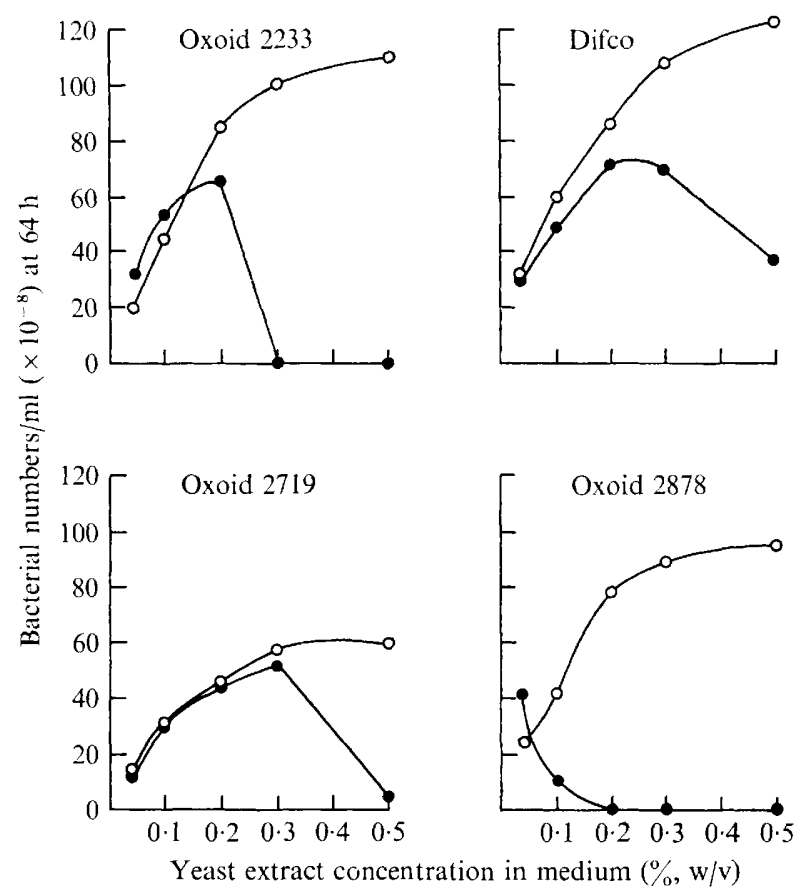

Fig. I. The effect of $\mathrm{Ca}^{2+}$ on the response of Rhizobium trifolii (J777) to increased concentrations of yeast extract. The medium was YEMB $\left(\mathrm{CaCO}_{3}\right.$ omitted in preparation) in acid-washed flasks, both with $(\mathrm{O})$ and without $(\bullet)$ added $0.022 \%(\mathrm{w} / \mathrm{v}) \mathrm{CaCl}_{2} \cdot 6 \mathrm{H}_{2} \mathrm{O}$.

traces of cystine, threonine, tyrosine, arginine, glutamine and tryptophan. All the yeast extracts were qualitatively similar except Oxoid 2719, which contained mainly glutamic acid and only very small amounts of other amino acids. The occurrence of alanine, serine and proline was not reported in some previously published analyses of yeast extracts (Strijdom \& Allen, 1966; Burton, 1967).

Glycine, $\mathrm{NaCl}$ and calcium in commercial yeast extracts. The concentrations of these substances in commercial yeast extracts are shown in Table 5. The glycine levels were approximately proportional to the $\alpha$-amino nitrogen content of the various extracts (Table $\mathrm{I}$ ). There was considerable variation in the calcium content, but $\mathrm{NaCl}$ concentrations were even more variable. Oxoid 2878 , which was more toxic than could be accounted for by its aminonitrogen content, contained much $\mathrm{NaCl}$. A high $\mathrm{NaCl}$ content would also be expected in yeast water prepared from washed brewer's yeast which showed extreme toxicity. 
Behaviour of glycine-adapted strains. Rhizobium trifolii strains $\mathrm{J} 7 \mathrm{I} 2$ and $\mathrm{J} 777$ were adapted to glycine as described in Methods. Colonies of these glycine-adapted strains on the twelve media described in Table $\mathrm{I}$ could be counted from the $\mathrm{I}: 10^{8}$ dilution in contrast with those of the untreated strains (Table $\mathrm{I}$ ) on the same media.

Plate counts on YEMA containing added divalent cations. Rhizobium trifolii strain $\mathrm{J} 7 \mathrm{I} 2$ was plated on YEMA containing $0.5 \%$ Oxoid 2878 . Addition of $0.022 \%$ (w/v) $\mathrm{CaCl}_{2} .6 \mathrm{H}_{2} \mathrm{O}$ or equivalent amounts of $\mathrm{MgCl}_{2} \cdot 6 \mathrm{H}_{2} \mathrm{O}, \mathrm{SrCl}_{2} \cdot 6 \mathrm{H}_{2} \mathrm{O}$ or $\mathrm{MnCl}_{2} \cdot 4 \mathrm{H}_{2} \mathrm{O}$ resulted in the recovery of $56,20,66$ or I I small colonies respectively at the I $1 \mathrm{I}^{8}$ dilution compared with no colonies on the control; a fivefold increase in the concentration of the additives gave I2 I, 97, 60 and 70 normal sized colonies respectively.

Effect of $\mathrm{Ca}^{2+}$ on the response of Rhizobium trifolii to increased concentration of yeast extract in the medium. The literature contains conflicting recommendations for the concentration of commercial yeast extract to be employed in yeast extract media. Consequently, the growth of strains $\mathrm{J} 7 \mathrm{I} 2$ and $\mathrm{J} 777$ was observed in YEMB containing $0.04,0.1,0.2,0.3$ and $0.5 \%$ yeast extract, both with and without $0.022 \% \mathrm{CaCl}_{2} \cdot 6 \mathrm{H}_{2} \mathrm{O}$. Both strains had similar behaviour, that of $\mathrm{J} 777$ with some of the yeast extracts is shown in Fig. I. Without calcium there was a response to yeast extract at the lower concentrations but the higher concentrations were distinctly toxic. With calcium, there was a response to increased concentration of yeast extract up to $0.5 \%$. At the lowest yeast extract concentrations, calcium appeared to have a slightly depressing effect in some instances.

Susceptibility of Rhizobium leguminosarum, $R$. meliloti and $R$. japonicum to yeast extract toxicity. Two strains each of $R$. leguminosarum, $R$. meliloti and $R$. japonicum were incubated on YEMA containing $0.5 \%$ Difco yeast extract, at $25{ }^{\circ} \mathrm{C}$. The two strains of $R$. meliloti grew well on this medium whereas the strains of the two other species were inhibited to the same extent as $R$. trifolii. Strains of $R$. trifolii, R. leguminosarum and $R$. japonicum were inhibited on standard YEMA containing 0.0025 to $0.005 \%$ of added glycine whereas the $R$. meliloti strains grew well with $0.02 \%$ glycine.

\section{DISCUSSION}

Although Jordan (1965) reported bacteroid-like forms in Rhizobium leguminosarum growing in YEMB containing $0.35 \%$ Difco yeast extract, many other workers have used and recommended media for rhizobia, containing higher yeast extract concentrations, without reference to growth failure. Commercial yeast extracts can be very variable in their toxicity to rhizobia. One sample (Oxoid 27I9) was not toxic at I \% concentration in YEMA while others were toxic at $0.3 \%$. In liquid media, even lower concentrations of yeast extract were toxic. The different species of rhizobia, and even strains within a species, showed variable susceptibility to the yeast extracts.

Glycine is the primary cause of yeast extract toxicity to Rhizobium trifolii; the inhibition is increased by monovalent cations and prevented by calcium. Glycine is an inhibitor of many species of bacteria. Its mode of action on rhizobia has not been studied but high concentrations of glycine ( $\mathrm{I}$ to $3 \%, \mathrm{w} / \mathrm{v}$ ) induce formation of sphaeroplasts, protoplasts and L-forms in other species (see McQuillen, 1960). Jordan (1965) reported that walls of $R$. leguminosarum were affected by yeast extract toxicity. He described evidence of reduced magnesium content of walls and suggested that high amino acid concentrations in the medium might possibly be chelating essential cations.

This study, however, shows that glycine has a specific effect which is unrelated to its chelating ability. The stability constants of amino acid-metal complexes (Martell \& Calvin, 
1952) indicate that several other amino acids ought to be equally effective in inducing calcium or magnesium deficiency but strip analysis of the yeast extract amino acid chromatogram showed that glycine was the only toxic substance present.

The toxic effect of the monovalent cations is also not clear, but may be due to depressed $\mathrm{Ca}^{2+}$ uptake. Kojima, Suda, Hotta \& Hamada (1970) showed that high concentrations of $\mathrm{NaCl}$ induced calcium deficiency in Lactobacillus bifidus. Other media components, such as hydrogen ion and phosphate concentration, would be expected to affect calcium availability also but have not been studied.

Bergersen (196I) and Vincent (1962) demonstrated that rhizobia growing in synthetic media require such low concentrations of $\mathrm{Ca}^{2+}(0.025$ to $0.35 \mathrm{mM})$ as would be expected to occur as impurities in crude media. Norris (1959) and Vincent (1970) questioned the necessity for including calcium salts in yeast extract media and recommended their exclusion, particularly from YEMB. This investigation shows that it may be advisable to include soluble calcium in media which contain undefined amounts of glycine and monovalent cations. Also, considerable caution is needed in the use of yeast extract media, particularly for quantitative recoveries of rhizobia.

I wish to thank Mr C. L. Masterson for his interest in the work and critical comments on the manuscript, Professor M. G. Harrington for helpful discussions and Mr A. Fanning for skilled technical assistance. The sodium, potassium, chloride and calcium analyses were performed by the Plant Analysis Section at Johnstown Castle. I am grateful to the Council of the Agricultural Institute for the award of a Research Scholarship.

\section{REFERENCES}

BERGERSEN, F.J.(I96I). The growth of Rhizobium in syntheticmedia. Australian Journal of Biological Sciences I4, 349-360.

Burton, J. C. (1967). Rhizobium culture and use. In Microbial Technology, pp. I-33. New York: Peppler and Rheingold.

BYRNe, E. (I968). Methods of Analysis. Wexford: An Foras Taluntais.

Fred, E. B., Baldwin, I. L. \& MCCoy, Elizabeth (1932). Root Nodule Bacteria and Leguminous Plants, Madison: University of Wisconsin.

FreY, S. W. (1964). The determination of copper, iron, calcium, sodium and potassium in beer by atomic absorption spectrophotometry. Atomic Absorption Newsletter 3, 127.

JoRDAN, D. C. (1965). On the cytology and synthetic capacities of natural and artifically produced bacteroids of Rhizobium leguminosarum. Canadian Journal of Microbiology Ir, 709-720.

Kojima, M., Suda, S., Hotta, S. \& Hamada, K. (1970). Induction of pleomorphy and calcium ion deficiency in Lactobacillus bifidus. Journal of Bacteriology 102, 217-220.

LevY, A. L. \& Chung, D. (1953). Two-dimensional chromatography of amino acids on buffered papers. Analytical Chemistry 25, 396-399.

MCQuillen, K. (1960). Bacterial protoplasts. In The Bacteria, vol. I, p. 280. Edited by I. C. Gunsalus and R. Y. Stanier. London: Academic Press.

Mann, F. G. \& Saunders, B. C. (I960). Practical Organic Chemistry, pp. 46 I-462. London: Longmans.

Martell, A. E. \& Calvin, M. (1952). Chemistry of the Metal Chelate Compounds. New Jersey: Prentice-Hall Inc.

Norris, D. O. (1959). The role of calcium and magnesium in the nutrition of Rhizobium. Australian Journal of Agricultural Research ro, 65I-698.

Strijdom, B. W. \& Allen, O. N. (I966). Medium supplementation with L- and D-amino acids relative to growth and efficiency of Rhizobium meliloti. Canadian Journal of Microbiology 12, 275-283.

VINCENT, J. M. (1962). Influence of calcium and magnesium on the growth of Rhizobium. Journal of General Microbiology 28, 653-663.

VinCENT, J. M. (1970). A Manual for the Practical Study of Root-Nodule Bacteria. Oxford and Edinburgh: Blackwell Scientific Publications. 